\title{
Overview of pneumococcal serotypes and genotypes causing diseases in patients with chronic obstructive pulmonary disease in a Spanish hospital between 2013 and 2016
}

This article was published in the following Dove Press journal:

Infection and Drug Resistance

Hisashi Shoji ${ }^{1, *}$

Daniel A Vázquez-Sánchez ${ }^{1, *}$

Aida Gonzalez-Diaz',2

Meritxell Cubero',2

Fe Tubau ${ }^{1,2}$

Salud Santos ${ }^{2,3}$

Dolores García-Somoza ${ }^{1,2}$

Josefina Liñares ${ }^{1,2}$

José Yuste ${ }^{2,4}$

Sara Martí1,2

Carmen Ardanuy ${ }^{1,2}$

'Microbiology Department, Hospital Universitari de Bellvitge, IDIBELL, University of Barcelona, Barcelona, Spain; ${ }^{2}$ CIBER de Enfermedades Respiratorias, ISCIII, Madrid, Spain; ${ }^{3}$ Respiratory Medicine Department, Hospital Universitari de Bellvitge, IDIBELL, University of Barcelona, Barcelona, Spain; ${ }^{4}$ Pneumococcal Reference Laboratory, Centro Nacional de Microbiología, ISCIII, Madrid, Spain

*These authors contributed equally to this work

Correspondence: Carmen Ardanuy; Sara Martí

Microbiology Department, Hospital Universitari de Bellvitge, IDIBELL, University of Barcelona, Feixa Llarga s/n, 08907, Barcelona, Spain

Tel +34932 607930

Fax +34932607547

Email c.ardanuy@bellvitgehospital.cat; smartinm@bellvitgehospital.cat
Background: Streptococcus pneumoniae is an important pathogen in chronic obstructive pulmonary disease (COPD). We aimed at showing the recent changes in the epidemiology of pneumococcal diseases in patients with COPD, especially after the introduction of the 13-valent pneumococcal conjugate vaccine (PCV13).

Methods: From 2013 to 2016, strains causing invasive pneumococcal disease (IPD), nonbacteremic pneumococcal pneumonia (non-BPP), and acute exacerbation of COPD (AE-COPD) were prospectively included. Antimicrobial susceptibility testing, serotyping, and genotyping were analyzed.

Results: We collected 345 pneumococci from 286 COPD patients (57 IPD, 78 non-BPP, and 210 AE-COPD). The most frequent serotypes were serotypes 3 (14.0\%), 8 (14.0\%), and 12F $(8.8 \%)$ in IPD; serotypes $3(16.7 \%), 11 \mathrm{~A}(9 \%), 9 \mathrm{~L} / \mathrm{N}(7.7 \%)$, and $23 \mathrm{~A}(7.7 \%)$ in non-BPP; and serotypes 11A (11\%), nontypeable (11\%), and 6C (10\%) in AE-COPD. Resistance rates were highest among AE-COPD strains. Penicillin resistance was associated with serotypes 11A (CC156) and 19A (CC320 and CC230). Compared with previous studies, fluoroquinolone resistance in AE-COPD increased (9.5\%), PCV13 serotypes decreased (31.6\%, 26.9\%, and 16.7\% for IPD, non-BPP, and AE-COPD, respectively), and serotype 11A-CC156 in AE-COPD and serotype 8 in IPD increased.

Conclusion: The epidemiology of pneumococcal disease in COPD changed after the introduction of PCV13 in children. Increases in the highly invasive serotype 8 among patients with IPD and in serotype 11A-CC156 among patients with AE-COPD could compromise the ability of current PCVs to prevent diseases. Vaccines with a greater coverage could improve the benefits of adult vaccination.

Keywords: Streptococcus pneumoniae, pneumococcal conjugate vaccine, chronic obstructive pulmonary disease, invasive pneumococcal disease

\section{Introduction}

Chronic obstructive pulmonary disease (COPD) is a major public health problem in developed countries which is characterized by high morbidity and mortality, principally due to recurrent acute exacerbations (AEs). ${ }^{1}$ According to the World Health Organization, 65 million people were estimated to suffer from COPD, among which there were more than three million deaths in 2005. ${ }^{2}$ However, its prevalence has since increased, and COPD is now the third leading cause of death worldwide. ${ }^{3}$ Patients with severe and very severe COPD are classified by the Global Initiative for Chronic Obstructive Lung 
Disease (GOLD) as GOLD III and GOLD IV, respectively, and usually have numerous AEs per year. ${ }^{4}$

Although several factors can lead to AE of COPD (AECOPD), viral and bacterial respiratory tract infections are the most common. Among these, Streptococcus pneumoniae is responsible for $>15 \%$ of AE-COPD. ${ }^{5}$ Therefore, the GOLD 2017 COPD guidelines recommended the administration of pneumococcal vaccines (mainly the 23-valent pneumococcal polysaccharide vaccine [PPSV23] and the 13-pneumococcal conjugated vaccine in adults) to prevent infection in patients with COPD. ${ }^{5,6}$ In pneumococci, the capsular polysaccharide is the most important virulence factor, and its diversity is the basis of both serotyping and vaccine formulation, with $>90$ serotypes known to exist. ${ }^{7}$ The different composition of the pneumococcal capsular polysaccharide (serotype) has been related to the invasive disease potential. The invasiveness classification is made regarding the prevalence of the different serotypes among colonization or invasive disease. ${ }^{7}$

The introduction of the 7-valent pneumococcal conjugate vaccine (PCV7) for children in early 2000, which was replaced by 13 -valent pneumococcal conjugate vaccine (PCV13) in 2010, reduced the incidence of invasive pneumococcal disease (IPD) in all age-groups and changed the epidemiology of pneumococcal infections. ${ }^{8-10}$ Since 2017 , PCV13 has been included in the official vaccination calendar for children aged $>5$ years. For adults with high-risk conditions, the proposed schedule is PCV13 followed by a booster with PPSV23 2 months later, while PPSV23 is recommended for adults in general. ${ }^{11}$

In pneumococci, antibiotic resistance has been associated with diseases such as COPD that receive multiple courses of antibiotics for exacerbations. ${ }^{12,13}$ In previous studies, we described changes in antimicrobial susceptibility and in the serotype and genotype distributions of pneumococci responsible for AE-COPD over a 12-year period, including the early PCV13 period. ${ }^{14}$

In this study, we show the recent changes in antimicrobial susceptibility and in pneumococcal serotypes and genotypes responsible for AE-COPD in the late PCV13 period (2013-2016). In addition, we analyze the invasiveness of pneumococcal serotypes among COPD patients.

\section{Materials and methods \\ Ethics}

Written informed consent was not considered necessary for the study, because it was a retrospective analysis of our usual daily work. However, patient data were anonymized for analysis, and any confidential information was protected according to the required national standards. This research was approved by the Clinical Research Ethics Committee of Bellvitge University Hospital (PR378/17), which also approved the publication of the research.

\section{Hospital setting, study design, and bacterial strains}

This prospective laboratory-based study included all pneumococcal isolates collected from adult patients ( $>18$ years) with IPD and non-IPD who attended the Hospital Universitari de Bellvitge. For the present study, isolates were selected if collected from patients with COPD in the period of 2013-2016. ${ }^{15}$

The COPD status of the patients was established according to the GOLD criteria. ${ }^{16}$ IPD was defined as the isolation of $S$. pneumoniae from a normally sterile site plus clinical symptoms of infection. Non-bacteremic pneumococcal pneumonia (non-BPP) was defined as the isolation of $S$. pneumoniae from a good-quality sputum sample $(<10$ squamous cells and $>25$ leucocytes per low-power field) in a patient with clinical signs and symptoms of pneumonia (fever, X-ray changes, and chest pain). Finally, an AECOPD was defined as any sustained increase in respiratory symptoms from baseline that required an increase in regular medication and hospital treatment. Two AE-COPD episodes were considered different when they occurred at least 1-month apart. Persistent strains were defined when two isolates of the same patient collected in different episodes had identical serotype and genotype.

Pneumococcal strains were identified by matrix-assisted laser desorption/ionization-time of flight plus optochin susceptibility and/or bile solubility. Antimicrobial susceptibility was tested by microdilution according to the criteria of the Clinical Laboratory Standard Institute. ${ }^{17,18}$

To understand the impact of PCV13 introduction in children on the serotype and genotype distribution of AE-COPD isolates, the study results for 2013-2016 were compared with data previously published by our group. ${ }^{14} \mathrm{PCV}$ s were licensed for childhood vaccination in 2001 (PCV7), 2009 (10-valent pneumococcal conjugate vaccine), and 2010 (PCV13). However, vaccination has been voluntary until 2017 because PCVs were not subsidized by official programs; therefore, the childhood vaccination rate in the study period was estimated to be about $60 \% .{ }^{19}$ Currently, PCV13 is subsidized by the official program for children (2, 4, and 11 months). ${ }^{11,19}$

\section{Serotyping and molecular typing}

Serotyping of AE-COPD strains was carried out by multiplex polymerase chain reaction (PCR), using a previously 
described methodology (https://www.cdc.gov/streplab/pcr. $\underline{\mathrm{html}})$. The invasive isolates and those in which the serotype was not identified by PCR were typed by Quellung reaction at the Spanish Reference Laboratory for Pneumococci in Majadahonda, Madrid, Spain. Genotyping was performed by pulse field gel electrophoresis (PFGE) and/or multilocus sequence typing (MLST) as described previously. ${ }^{15}$ All pneumococcal strains were tested by PFGE, and representative strains of the major PFGE clusters (defined by those accounting for four or more isolates) were tested by MLST. When a major PFGE cluster accounted for isolates of more than one serotype, at least one isolate of each serotype-PFGE cluster combination was subjected to MLST.

\section{Statistical analysis}

Statistical analyses were performed using SPSS for Windows, Version 14.0 (SPSS Inc., Chicago, IL, USA). Serotypes, genotypes, and antimicrobial susceptibility in patients with pneumonia and AE-COPD were compared using the $\chi^{2}$ or Fisher's exact tests, as appropriate. Two-sided $p$-values $<0.05$ were considered statistically significant.

\section{Results and discussion \\ Patient characteristics and antibiotic susceptibility}

During the study period, 1409 pneumococcal strains were isolated in our hospital. Of these, 1064 were excluded because they were collected from non-COPD patients $(n=949)$, were isolated from asymptomatic COPD patients $(n=107)$, or were not available for serotype analysis $(n=8)$. Figure 1 shows the workflow of the study. Consequently, we finally included 345 pneumococcal isolates from 286 adult patients with COPD.

The median age of the 286 included patients was 72 years (range 38-94), and most (85.5\%) of the patients were male. Of the 345 isolates, we collected 57 (16.5\%) during episodes of IPD, 78 (22.6\%) during episodes of non-BPP, and 210 $(60.9 \%)$ during AE-COPD (Figure 1). Among the IPD episodes, 45 were bacteremic pneumonia, three were meningitis, seven were primary bacteremia, and two were others. The severity of airflow obstruction at the time of infection was known in 284 cases, and 24 cases were classified as GOLD I (7\%), 90 as GOLD II (26.1\%), 111 as GOLD III (32.2\%), and 59 as GOLD IV (17.1\%) as shown in Table 1. The GOLD status was not known in the remaining 61 cases because they were classified as having COPD based on clinical diagnosis, without a spirometric evaluation.

In 33 patients, more than one isolate was collected from different episodes occurring $>1$ month apart (ranging from two to nine episodes per patient). Among them, 19 patients had more than two AE-COPD episodes, one patient had two non-BPP episodes, and two patients had two IPD episodes; 10 patients had $\geq 1$ AE-COPD and $\geq 1$ non-BPP episodes; finally, 1 patient had 1 AE-COPD episode and 1 IPD episode. Comparing serotypes and genotypes between episodes, persistent strains (defined as both isolates sharing identical serotypes and genotypes) were only identified for AE-COPD in 10 patients. However, the serotype-genotype combinations for each of these persistent strains were different (6C-ST386, 11A-ST62, 11A-ST6521, 19A-ST81, 19A-ST320, 19A-ST276, 16F-ST30, 19F-ST8359, and 23BST2372). Although we have found a high diversity among these strains when compared with previous results, the rate of persistence among patients with more than one episode remained stable. ${ }^{20}$

Table 2 summarizes the antibiotic nonsusceptibility of pneumococcal isolates collected during IPD, nonBPP, and AE-COPD episodes. Although most isolates were collected from respiratory infections, the $\beta$-lactam meningeal break points were also used in the analysis due to its epidemiological value. Overall, there were differences in susceptibility between groups, including $\beta$-lactams, macrolides, and fluoroquinolones, with higher resistance rates among AE-COPD isolates than among isolates from other infection types. This fact could reflect the high usage of antibiotics to treat AE-COPD, and it could favor the selection of drug-resistant strains. ${ }^{21}$ Compared with previous reports, antibiotic resistance rates for pneumococcal disease in patients with COPD remained stable in the study period, with the exception of levofloxacin, which increased from $3.5 \%$ in the period of 2001-2008 to $9.52 \%$ in the period of 2013-2016 among AE-COPD isolates. It is possible that the use of fluoroquinolones in these patients has favored the selection of mutations in the quinolone resistance-determining regions among persistent strains. ${ }^{15,21}$

\section{Current distribution of pneumococcal serotypes}

Figure 2 shows the distribution of pneumococcal serotypes by disease type. Overall, as shown in Table 3, serotypes $11 \mathrm{~A}$ $(n=33,9.6 \%)$, nontypeable $(n=27,7.8 \%), 3(n=26,7.5 \%)$, 6C $(n=25,7.2 \%)$, and 19A $(n=21,6.1 \%)$ were the most frequent. However, differences were observed according to the disease type: Serotypes $3(n=8,14.0 \%), 8(n=8,14.0 \%)$, and $12 \mathrm{~F}(\mathrm{n}=5,8.8 \%)$ were the most frequent in IPD; serotypes $3(\mathrm{n}=13,16.7 \%), 11 \mathrm{~A}(\mathrm{n}=7,9 \%), 9 \mathrm{~L} / \mathrm{N}(\mathrm{n}=6,7.7 \%)$, and 


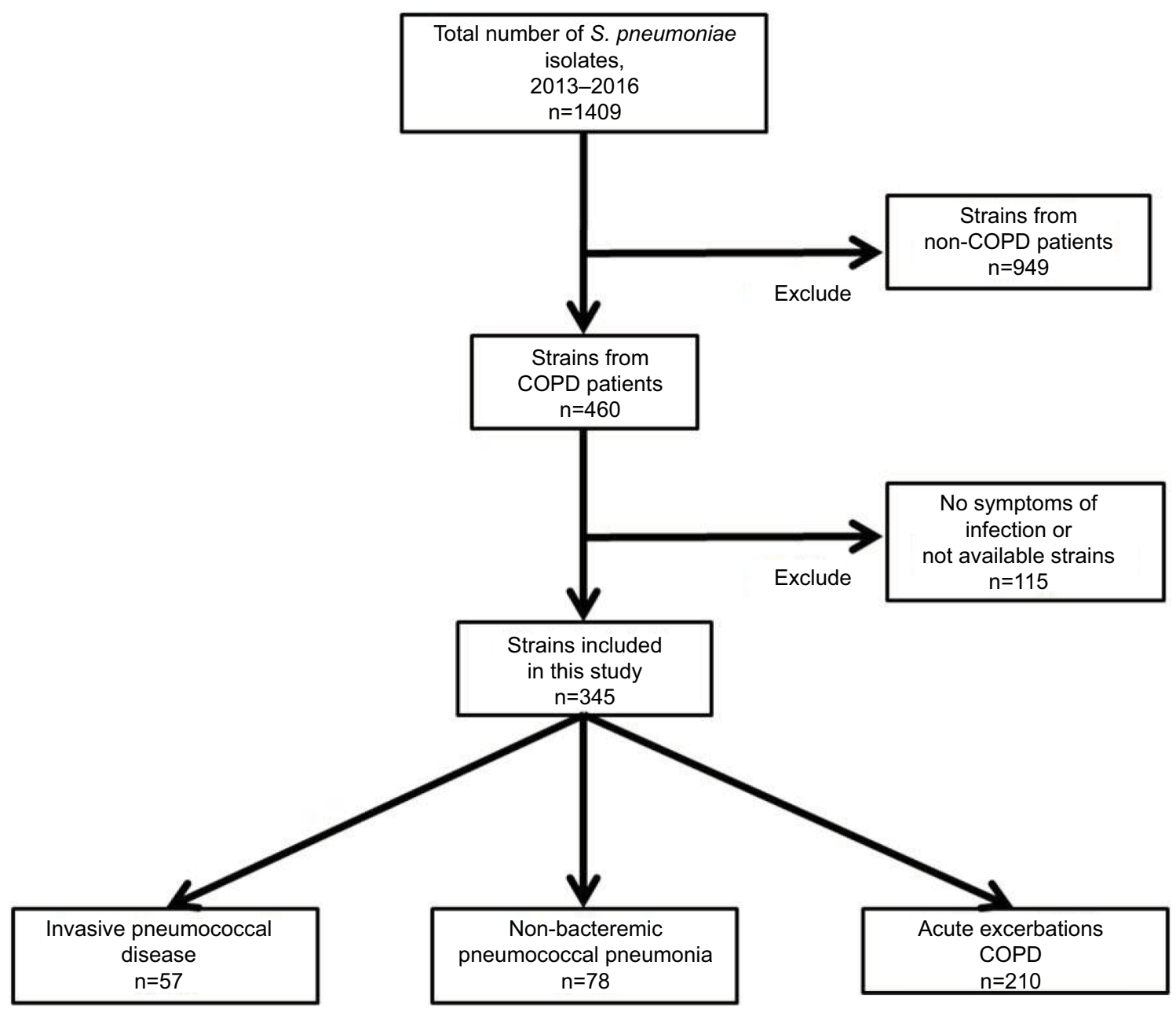

Figure I Flowchart representing the methodology used for the selection of Streptococcus pneumoniae isolates in patients with COPD. Abbreviation: COPD, chronic obstructive pulmonary disease.

23A $(n=6,7.7 \%)$ were the most frequent in non-BPP; and serotypes $11 \mathrm{~A}(\mathrm{n}=23,11 \%)$, non-typeable $(\mathrm{n}=23,11 \%)$, and $6 \mathrm{C}(\mathrm{n}=21,10 \%)$ were the most frequent in AE-COPD. The respective coverages of vaccines for IPD, non-BPP, and AE-COPD were as follows: 5.3\%, 1.3\%, and 7.6\% for PCV7; $31.6 \%, 26.9 \%$, and $16.7 \%$ for PCV13; and $35.1 \%, 30.8 \%$, and $20.0 \%$ for the upcoming PCV 15.22

Compared with previous reports, the frequency of PCV13 serotypes in AE-COPD isolates has decreased between periods, from $55.1 \%$ in $2001-2004$, to $40.3 \%$ in $2005-2008$, to $28.8 \%$ in $2009-2012$, and to $16.7 \%$ in 2013-2016 as shown in Figure 3. ${ }^{14,15}$ These likely reflect a serotype replacement on pneumococcal disease in COPD patients probably by the impact of childhood vaccination. In fact, a prospective multicenter study performed in Spain after the introduction of PCV13 for children showed a $50 \%$ reduction of adult IPD due to PCV13. ${ }^{19}$ Despite this indirect and beneficial impact of childhood vaccination, PCV13 serotypes are still found in COPD patients. This fact could be justified by several factors: first, COPD patients could be persistently colonized by pneumococci (even PCV13 serotypes); second, COPD patients are not vaccinated with PCV13; and third, there are PCV13 serotypes rarely found in children (ie, serotype 3 ); then, an exclusively childhood vaccination strategy with PCV13 could barely impact on the prevalence of these serotypes in adults. Then, the prevention of pneumococcal infections in COPD patients deserves other strategies. In fact, a recent prospective observational study of patients with COPD demonstrated that those who did not receive the PCV13 vaccine had triple the risk of 
Table I Characteristics of COPD patients with pneumococcal infections

\begin{tabular}{|c|c|c|c|c|c|c|}
\hline & \multicolumn{2}{|c|}{ IPD } & \multicolumn{2}{|c|}{ non-BPP } & \multicolumn{2}{|c|}{ AE-COPD } \\
\hline & $\%$ & Number of isolates & $\%$ & Number of isolates & $\%$ & Number of isolates \\
\hline Total & 57 & 16.5 & 78 & 22.60 & 210 & 60.9 \\
\hline Sex (male) & 37 & 64.9 & 68 & 87.18 & 190 & 90.5 \\
\hline Age (median) & 69 & & 73 & & 73 & \\
\hline \multicolumn{7}{|c|}{ COPD GOLD status } \\
\hline GOLD I & 8 & 14.0 & 7 & 9 & 9 & 4.3 \\
\hline GOLD II & 16 & 28.1 & 27 & 34.6 & 47 & 22.4 \\
\hline GOLD III & 13 & 22.8 & 29 & 37.2 & 69 & 32.9 \\
\hline GOLD IV & 2 & 3.5 & 8 & 10.2 & 49 & 23.3 \\
\hline Not available & 18 & 31.6 & 7 & 9 & 36 & 17.1 \\
\hline
\end{tabular}

Abbreviations: AE-COPD, acute exacerbation of COPD; COPD, chronic obstructive pulmonary disease; GOLD, Global Initiative for Chronic Obstructive Lung Disease; IPD, invasive pneumococcal disease; non-BPP, non-bacteremic pneumococcal pneumonia.

Table 2 Antibiotic nonsusceptibility rates of pneumococcal isolates collected from IPD, non-BPP, and AE-COPD in the period of 2013-2016

\begin{tabular}{|c|c|c|c|c|c|c|c|c|}
\hline \multirow[b]{2}{*}{ Antibiotics } & \multicolumn{2}{|l|}{ IPD } & \multicolumn{2}{|c|}{ non-BPPa } & \multicolumn{2}{|c|}{ AE-COPD } & \multicolumn{2}{|l|}{ Total } \\
\hline & $n=57$ & $\% R$ & $n=78$ & $\% R$ & $n=210$ & $\% R$ & $n=345$ & $\% \mathbf{R}$ \\
\hline Penicillin ${ }^{b}$ & 15 & 26.32 & 15 & 19.23 & 96 & $45.7 I^{c}$ & 126 & 36.52 \\
\hline $0.12-1 \mathrm{mg} / \mathrm{L}$ & 10 & 17.54 & 8 & 10.26 & 60 & 28.57 & 78 & 22.61 \\
\hline $2 \mathrm{mg} / \mathrm{L}$ & 3 & 5.26 & 3 & 3.85 & 26 & 12.38 & 32 & 9.28 \\
\hline$\geq 4 \mathrm{mg} / \mathrm{L}^{\mathrm{d}}$ & 2 & 3.51 & 4 & 5.13 & 10 & 4.76 & 16 & 4.64 \\
\hline Cefotaxime $^{\mathrm{b}}$ & 6 & 10.53 & 8 & 10.26 & 25 & 11.90 & 39 & 11.30 \\
\hline I mg/L & 5 & 8.77 & 5 & 6.41 & 20 & 9.52 & 30 & 8.70 \\
\hline$\geq 2 \mathrm{mg} / \mathrm{L}^{\mathrm{d}}$ & I & 1.75 & 3 & 3.85 & 5 & 2.38 & 9 & 2.61 \\
\hline Amoxicillin & 2 & 3.51 & 5 & 6.41 & 25 & $11.90^{\circ}$ & 32 & 9.28 \\
\hline $4 \mathrm{mg} / \mathrm{L}^{\mathrm{d}}$ & 1 & 1.75 & 5 & 6.41 & 21 & 10.00 & 27 & 7.83 \\
\hline$\geq 8 \mathrm{mg} / \mathrm{L}^{\mathrm{d}}$ & I & 1.75 & 0 & 0.00 & 4 & 1.90 & 5 & 1.45 \\
\hline Erythromycin & 9 & 15.79 & 11 & 14.10 & 80 & $38.10^{c}$ & 100 & 28.99 \\
\hline Clindamycin & 8 & 14.04 & 9 & 11.54 & 72 & $34.29^{c}$ & 89 & 25.80 \\
\hline Tetracycline & 18 & 31.58 & 16 & 20.51 & 87 & $41.43^{c}$ & 121 & 35.07 \\
\hline Chloramphenicol & 6 & 10.53 & 5 & 6.41 & 9 & 4.29 & 20 & 5.80 \\
\hline Cotrimoxazole & 12 & 21.05 & 16 & 20.51 & 69 & 32.86 & 97 & 28.12 \\
\hline Levofloxacin & I & 1.75 & 1 & 1.28 & 20 & 9.52 & 22 & 6.38 \\
\hline Multiresistance & 12 & 21.05 & 10 & 12.82 & 77 & $36.67^{c}$ & 99 & 28.70 \\
\hline
\end{tabular}

Notes: ${ }^{2}$ There were no statistically significant differences among resistance rates of IPD and non-BPP; boverall nonsusceptible following meningeal criteria; ${ }^{\text {'resistance rates }}$ of AE-COPD pneumococci significantly higher $(p<0.05)$ than among IPD or non-BPP isolates; ${ }^{d}$ nonsusceptible for nonmeningeal infections. \%R indicates the percentage of resistance to each antibiotic among the number that is given on each group (IPD, non-BPP, AECOPD and Total).

Abbreviations: AE-COPD, acute exacerbation of chronic obstructive pulmonary disease; IPD, invasive pneumococcal disease; non-BPP, non-bacteremic pneumococcal pneumonia.

COPD-related hospitalizations compared with vaccinated patients. ${ }^{23}$ The use of PCVs to prevent pneumococcal disease in adult patients with COPD could improve the beneficial effects of childhood vaccination, especially for the prevention of IPD and non-BPP. In contrast, the high frequency of nonvaccine serotypes among the AE-COPD isolates emphasizes the need for broader vaccine strategies. The sequential vaccination with PCV13 plus the PPSV23 could improve the benefits in at-risk patients, as recommended. ${ }^{6}$ Many penicillin-resistant strains (minimum inhibitory concentration $[\mathrm{MIC}]>1 ; n=48$ ) were associated with serotypes 11A (all related to CC156; $\mathrm{n}=21$ ), 19A (mainly related to $\mathrm{CC} 320$ or CC230; $\mathrm{n}=11$ ), and 19F (mainly related to ST8359; $\mathrm{n}=5$ ). Macrolide resistance was mainly associated with serotypes 6C (CC386) and 19A (CC320 and $\mathrm{CC} 230$ ). Moreover, these latter two serotypes, and their related clonal complexes, were also the major contributors to multidrug resistance.

\section{Invasiveness of serotypes}

Three serotypes $(8,3$, and $12 \mathrm{~F})$ were more prone to cause invasive disease based on their significant ORs comparing 
Table 3 Serotype distribution among IPD and AE-COPD in COPD patients

\begin{tabular}{|c|c|c|c|c|c|c|}
\hline & \multicolumn{2}{|l|}{ IPD } & \multicolumn{2}{|l|}{ AE-COPD } & \multirow[t]{2}{*}{ OR } & \multirow[t]{2}{*}{$95 \% \mathrm{Cl}$} \\
\hline & Number of isolates & $\%$ & Number of isolates & $\%$ & & \\
\hline Total & 57 & 16.5 & 210 & 60.9 & & \\
\hline \multicolumn{7}{|l|}{ Serotype } \\
\hline PCV7 & 3 & 5.26 & 16 & 7.6 & 0.67 & $(0.19-2.39)$ \\
\hline 4 & 0 & 0 & 0 & 0 & - & $(-1-)$ \\
\hline $6 B$ & 0 & 0 & I & 0.5 & 0.00 & $(0 /-)$ \\
\hline $9 \mathrm{~V}$ & 0 & 0 & 1 & 0.5 & 0.00 & $(0 /-)$ \\
\hline 14 & 2 & 3.51 & 0 & 0 & $\infty$ & $(-1 \infty)$ \\
\hline $18 \mathrm{C}$ & 0 & 0 & 2 & $\mathrm{I}$ & 0.00 & $(0 /-)$ \\
\hline $19 \mathrm{~F}$ & I & 1.75 & 11 & 5.2 & 0.32 & $(0.04-2.55)$ \\
\hline $23 \mathrm{~F}$ & 0 & 0 & 1 & 0.5 & 0.00 & $(0 /-)$ \\
\hline PCVI3 & 18 & 31.6 & 35 & 17 & 2.31 & $(1.18-4.49)$ \\
\hline Additional PCVI3 & 15 & 26.3 & 19 & 9 & 6.50 & $(3.03-13.91)$ \\
\hline 1 & 1 & 1.75 & 0 & 0 & 0.00 & $(0 /-)$ \\
\hline 3 & 8 & $14.0^{\mathrm{a}}$ & 5 & 2.4 & 6.69 & (2.10-21.35 \\
\hline 5 & 0 & 0 & 0 & 0 & - & $(-/-)$ \\
\hline $6 \mathrm{~A}$ & 0 & 0 & 0 & 0 & - & $(-1-)$ \\
\hline $7 F$ & 3 & 5.26 & I & 0.5 & 11.61 & $(1.18-113.84)$ \\
\hline $19 A$ & 3 & 5.26 & 13 & 6.2 & 0.84 & $(0.23-3.06)$ \\
\hline Non-PCVI3 & 39 & 68.4 & 175 & 83 & 0.43 & $(0.22-0.84)$ \\
\hline $6 C$ & 3 & 5.26 & 21 & 10 & 0.50 & $(0.14-1.74)$ \\
\hline 8 & 8 & $14.0^{\mathrm{a}}$ & 2 & 1 & 16.98 & $(3.5-82.47)$ \\
\hline 9N/L & 3 & 5.26 & 5 & 2.4 & 2.28 & $(0.53-9.83)$ \\
\hline $10 \mathrm{~A}$ & 2 & 3.51 & 8 & 3.8 & 0.92 & $(0.19-4.45)$ \\
\hline IIA & 3 & 5.26 & 23 & 11 & 0.45 & $(0.13-1.56)$ \\
\hline $12 \mathrm{~F}$ & 5 & $8.8^{a}$ & 0 & 0 & $\infty$ & $(-1 \infty)$ \\
\hline $16 \mathrm{~F}$ & 0 & 0 & 7 & 3.3 & 0.00 & $(0 /-)$ \\
\hline $17 F$ & 2 & 3.51 & 2 & I & 3.80 & $(0.52-27.45)$ \\
\hline $22 \mathrm{~F}$ & 2 & 3.51 & 6 & 2.9 & 1.23 & $(0.24-6.29)$ \\
\hline $23 \mathrm{~A}$ & 3 & 5.26 & 10 & 4.8 & 1.11 & $(0.29-4.17)$ \\
\hline $23 B$ & 3 & 5.26 & 8 & 3.8 & 1.40 & $(0.36-5.46)$ \\
\hline $24 \mathrm{~F}$ & 0 & 0 & 8 & 3.8 & 0.00 & $(0 /-)$ \\
\hline 31 & 3 & 5.26 & 13 & 6.2 & 0.84 & $(0.23-3.06)$ \\
\hline $35 B$ & 2 & 3.51 & 8 & 3.8 & 0.91 & $(0.18-4.44)$ \\
\hline Others & 0 & 0 & 54 & 26 & 0.00 & $(0 /-)$ \\
\hline
\end{tabular}

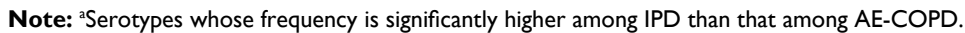

Abbreviations: AE-COPD, acute exacerbation of COPD; COPD, chronic obstructive pulmonary disease; IPD, invasive pneumococcal disease; PCV7, 7-valent pneumococcal conjugate vaccine; PCVI3, I3-valent pneumococcal conjugate vaccine.

IPD with AE-COPD isolates (Table 3). In a recent study performed in Sweden, serotype 8 has been shown to have high invasive disease potential based on the difference in serotype distribution between nasopharyngeal colonization (a prerequisite to disease) and invasive disease. ${ }^{24}$ Moreover, we observed a notable increase of serotype 8 among IPD (from 6.4\% in the period of 2001-2008 to 14\% in the period of 2013-2016), as has been reported in other European countries. ${ }^{25,26}$ The invasive disease potential of serotype 3, by contrast, is more controversial. For example, a low disease potential or lineage-dependent invasive disease potential has been shown for this serotype, ${ }^{7,27}$ even though the study from
Sweden showed this serotype to have high invasiveness. ${ }^{24} \mathrm{In}$ the same way, our finding of the low invasiveness of serotype $11 \mathrm{~A}$ is in agreement with the findings of the Swedish report on this serotype. ${ }^{24}$

Regarding invasive disease potential, slight differences in methodology should be considered when drawing conclusions. In our series, the frequency of serotype 3 isolates was compared between two types of pneumococcal disease (AE-COPD and IPD). However, classical studies regarding the invasiveness of pneumococcal serotypes compared the proportions of serotypes causing IPD or colonizing children (no disease). Despite these differences, serotype 3 appears 


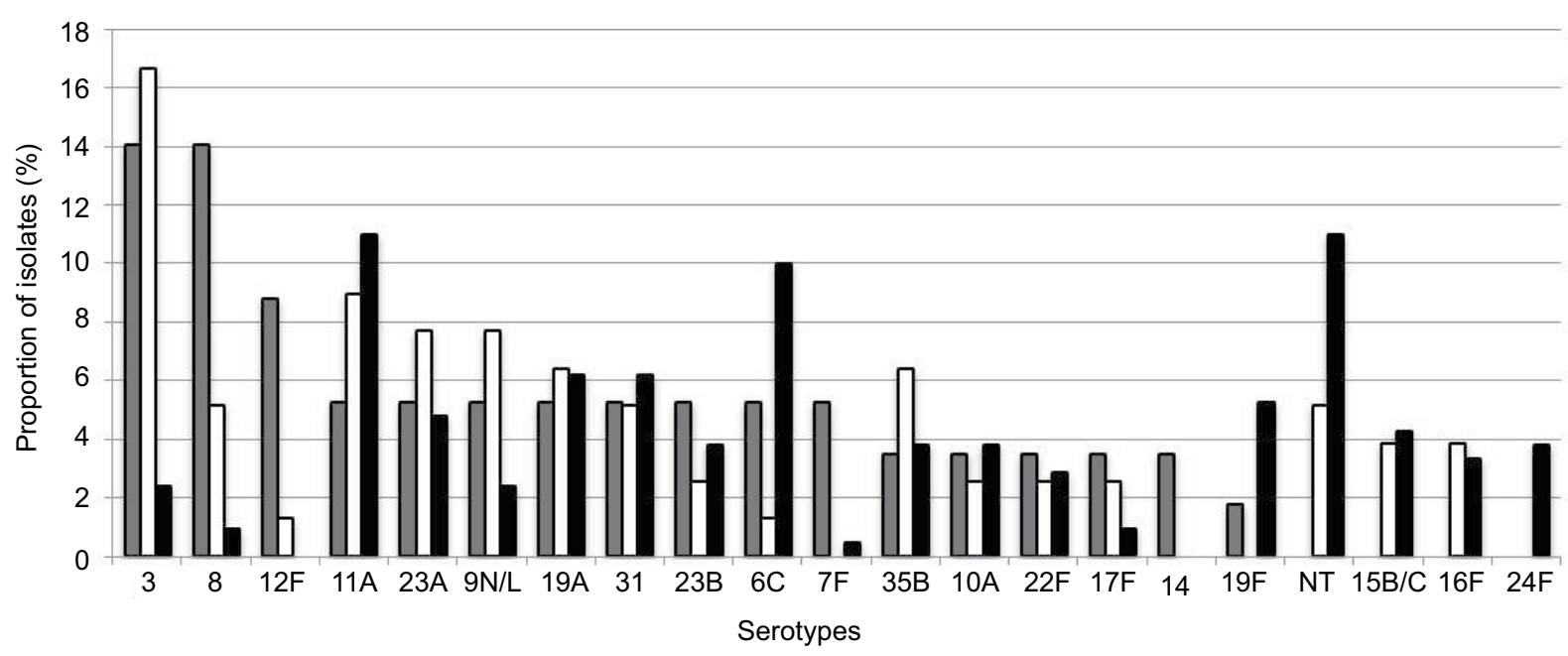

Figure 2 Distribution of pneumococcal serotypes among IPD, non-BPP, and AE-COPD.

Notes: Bars represent the proportion of each serotype among different disease types. Gray bars show IPD, white bars show non-BPP isolates, and black bars show AECOPD isolates.

Abbreviations: AE-COPD, acute exacerbation of chronic obstructive pulmonary disease; IPD, invasive pneumococcal disease; non-BPP, non-bacteremic pneumococcal pneumonia.

to be a major cause of pneumococcal disease in patients with COPD.

\section{Changes in serotype distribution in the late PCVI 3 period: emerging clones in AE-COPD}

Although the impact of PCV13 introduction has been extensively analyzed for both children and adults with IPD, information about its impact of clonal composition is scarce. Such knowledge of the genetic background of serotypes is important when seeking to identify emerging or recombinant clones. Therefore, we compared the current serotype distribution of AE-COPD isolates with a historical period (Table S1) ${ }^{14}$ As expected, most of the PCV13 serotypes (3, 23F, 14 , $9 \mathrm{~V}$, and 6A) decreased significantly (Table S1). Despite the decrease in the frequency of serotype 3 among AECOPD episodes over the study period, this serotype remains as a leading cause of IPD (together with serotype 8, 14\% each). Although we did not have an explanation for this event, we have noticed a progressive change in the clonal distribution of serotype 3 in COPD and other adult patients in our area. ${ }^{10,19}$ Currently, the major clone is the widely disseminated serotype 3 clone (CC180) that probably could have advantages to improve invasiveness. On the other hand, the frequency of serotype 19A remained stable $(6.2 \%-6.6 \%)$, which was mainly linked to two multidrug-resistant lineages (CC230 and ST320; shown in Figure 4; Tables S2 and S3). Among the non-PCV13 serotypes, there were notable increases in the frequencies of serotypes $6 \mathrm{C}, 11 \mathrm{~A}$, and 15B/C.

Perhaps the most noteworthy result in this comparison was the shift in the clonal composition of serotype 11A, with an overall decrease in CC62 that paralleled the increase in CC156, which is related to ST6521 (Figure 4; Table S3). Moreover, it was interesting to analyze the changes in the prevalence of CC156 among AE-COPD episodes. In a previous study, we showed that it decreased mainly in response to decreases in vaccine serotypes $9 \mathrm{~V}$ and $14 .{ }^{14}$ However, in the period of 2013-2016, there was a significant increase in CC156, reaching frequencies similar to those prior to the introduction of PCVs, but with a change in the serotype composition. Whereas all CC156 isolates belonged to serotypes 14 and $9 \mathrm{~V}$ in the periods of 2001-2004 and 2005-2008, nearly all CC156 isolates (19 of 20 isolates) were serotype 11A in the period of 2013-2016 (Figure 4; Table S3). This emerging recombinant clone was first detected in 2007 in Spain, when it was associated with both invasive and noninvasive diseases. ${ }^{28}$

The CC156 recombinant clone has shown a high potential to be able to avoid the host immune response and a high ability to produce biofilms, both of which are important in the pathogenesis of AE-COPD. ${ }^{28}$ Moreover, our present results have shown that the frequency of this vaccine escape recombinant clone is increasing among patients with 


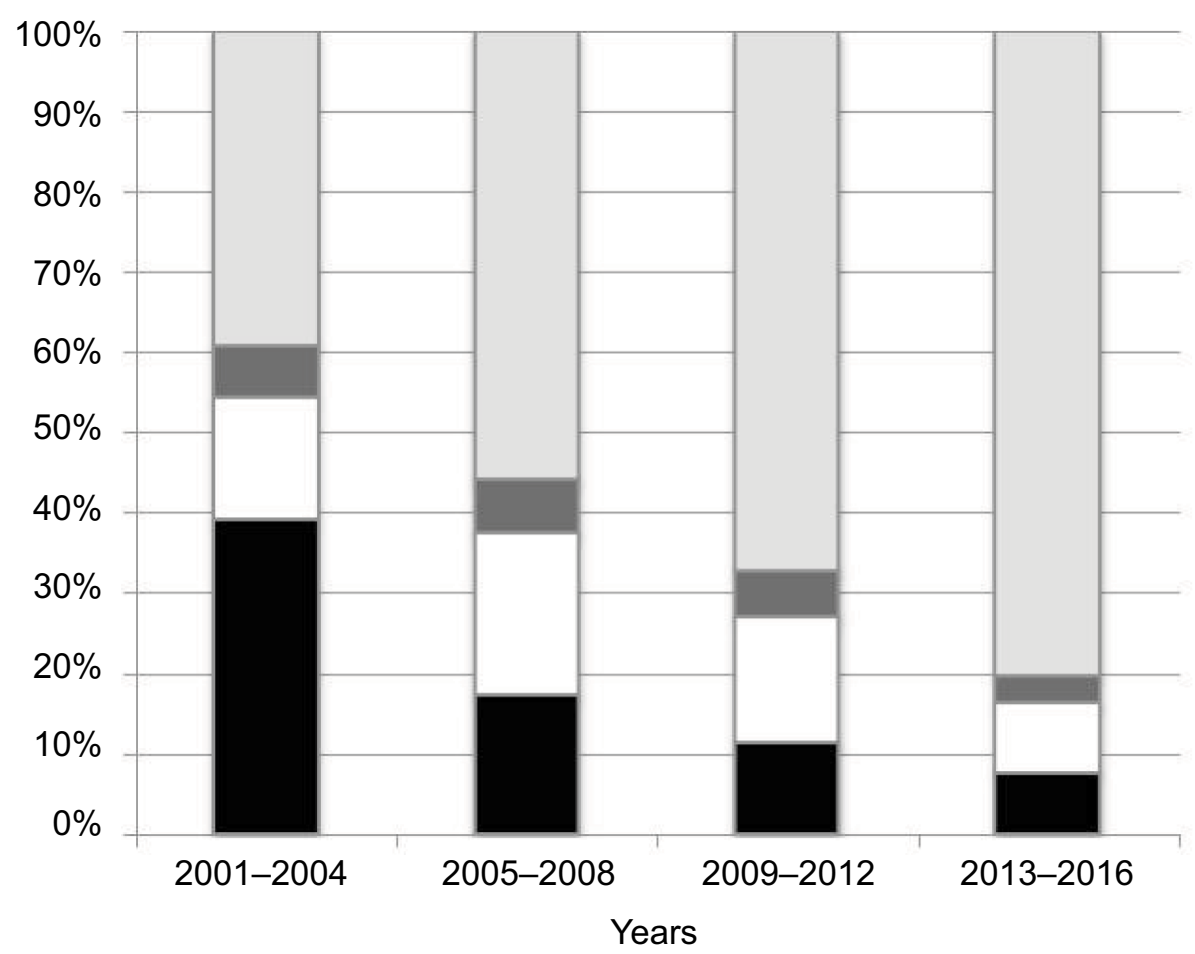

Figure 3 Distribution of pneumococcal serotypes by vaccine groups among AE-COPD isolates.

Notes: Black bars show PCV7 serotypes, white bars show additional PCVI3 serotypes, dark gray bars show additional PCVI5 serotypes, and gray bars show non-PCVI3 serotypes.

Abbreviations: AE-COPD, acute exacerbation of chronic obstructive pulmonary disease; PCV7, 7-valent pneumococcal conjugate vaccine; PCVI3, I3-valent pneumococcal conjugate vaccine; PCVI5, I5-valent pneumococcal conjugate vaccine.

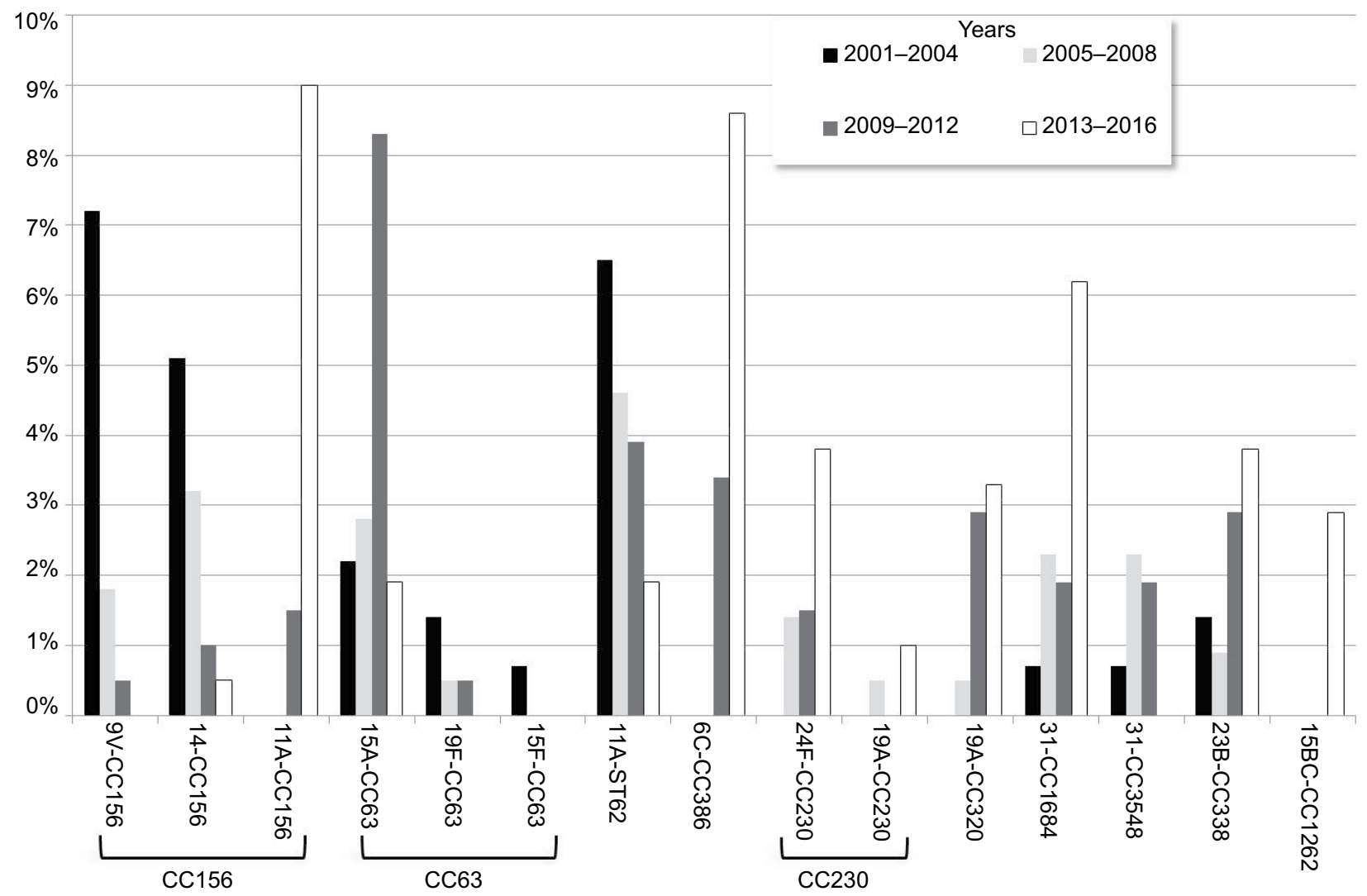

Figure 4 Main changes in the distribution of genotype-serotype combinations among AE-COPD.

Notes: Bars showed the proportion of the different genotype-serotype combinations among AE-COPD pneumococci. Colors differentiate periods. Abbreviation: AE-COPD, acute exacerbation of chronic obstructive pulmonary disease. 
COPD. The combination of damaged bronchial epithelium and impaired immunity of these patients, together with the pathogenic characteristics of this recombinant strain, could account for this rise. The most worrisome feature, however, is the high-level resistance of this clone to amoxicillin, which is frequently prescribed for AE-COPD. Amoxicillin use could even compromise the evolution and outcomes of the disease.

Another important issue is the declining frequency of CC63. Although this showed an increasing trend in the early PCV13 period (2009-2012), its frequency is currently very low. However, clonal fluctuations could account for these changes. ${ }^{10}$ The continuous increase of CC386 (serotype 6C) is yet another important issue, because this multidrug-resistant clone has resistance to macrolides and lincosamides and has been detected in neighboring European countries such as France or Portugal as a cause of pneumococcal disease, especially in adults. ${ }^{29-31}$ It is possible that the increased use of azithromycin to treat patients with advanced COPD pathology, because of their possible anti-inflammatory activity, could have contributed to the high prevalence of this macrolide- and multidrug-resistant clone. ${ }^{32}$

We observed the spread of two other clones: CC1684 related to serotype 31 and CC2372 related to serotype 23B, as previously described. ${ }^{33,34}$ Both were sporadically detected before 2013 and in this study accounted for $6.2 \%$ and $3.8 \%$ of AE-COPD isolates, respectively. CC1684 is a $\beta$-lactam- and macrolide-susceptible clone that has been identified among cotrimoxazole-resistant and cotrimoxazole-susceptible serotype 31 isolates colonizing children in Thailand. ${ }^{34}$ All serotype 23B-ST2372 isolates were penicillin-resistant (MIC range $=0.25-1 \mu \mathrm{g} / \mathrm{mL}$ ) and cotrimoxazole-resistant.

The major limitation of our study is that it was performed in a single hospital and only reflects the local epidemiology of patients with COPD in this area. However, performing a comparison with a historical series allowed us to analyze the recent changes in pneumococcal diseases in this population. Another limitation is the lacking data about PPSV23 vaccination in these patients.

\section{Conclusion}

We have shown a change in the serotype distribution of disease-causing pneumococci in patients with COPD. The spread of a serotype $11 \mathrm{~A}$ recombinant clone (11A$\mathrm{CC} 156)$ as a cause of AE-COPD is worrisome because it has strong $\beta$-lactam resistance. Another worrisome change is the increase in the highly invasive serotype 8 that could compromise the effectiveness of current conjugate vaccines in the prevention of IPD in COPD patients. New conjugated vaccines that include these emerging serotypes, or preferably nonserotype vaccines, are needed to preserve the benefits of vaccination in patients with COPD and the overall population.

\section{Acknowledgments}

We thank the staff of Hospital Universitari de Bellvitge for their daily contributions, which made this project possible. This study was supported by grants from Fondo de Investigaciones Sanitarias de la Seguridad Social PI14/00627, PI16/00977, INT 2015/0186, and INT 2016/0177 and from Centro de Investigación Biomédica en Red (CIBER) de Enfermedades Respiratorias (CIBERES CB06/06/0037), an initiative of the Instituto de Salud Carlos III, Madrid, Spain. Financial support was also provided by the European Regional Development Fund. The results have been presented, in part, at the 27th European Congress of Clinical Microbiology and Infectious Diseases, Vienna, Austria, April 22-25, 2017.

\section{Disclosure}

$\mathrm{CA}$ and JL received funding from Pfizer, unrelated to the present study. The authors report no other conflicts of interest in this work.

\section{References}

1. Buist AS, McBurnie MA, Vollmer WM, et al. International variation in the prevalence of COPD (The BOLD Study): a population-based prevalence study. Lancet. 2007;370(9589):741-750.

2. World Health Organization. Chronic respiratory diseases, chronic obstructive pulmonary disease (COPD). Geneva: World Health Organization; 2017. Available from: http://www.who.int/respiratory/copd/ burden/en/. Accessed October 5, 2017.

3. Lozano R, Naghavi M, Foreman K, et al. Global and regional mortality from 235 causes of death for 20 age groups in 1990 and 2010: a systematic analysis for the Global Burden of Disease Study 2010. Lancet. 2012;380(9859):2095-2128.

4. Hurst JR, Vestbo J,Anzueto A, et al. Susceptibility to exacerbation in chronic obstructive pulmonary disease. NEngl J Med. 2010;363(12):1128-1138.

5. Cimen P, Unlu M, Kirakli C, et al. Should patients with COPD be vaccinated? Respir Care. 2015;60(2):239-243.

6. Global Initiative for Chronic Obstructive Lung Disease. GOLD 2017 Global Strategy for the Diagnosis, Management and Prevention of COPD. Available from: https://goldcopd.org/gold-2017-global-strategydiagnosis-management-prevention-copd/. Accessed July 31, 2018.

7. Brueggemann AB, Peto TE, Crook DW, Butler JC, Kristinsson KG, Spratt BG. Temporal and geographic stability of the serogroup-specific invasive disease potential of Streptococcus pneumoniae in children. $J$ Infect Dis. 2004;190(7):1203-1211.

8. Whitney CG, Farley MM, Hadler J, et al. Decline in invasive pneumococcal disease after the introduction of protein-polysaccharide conjugate vaccine. $N$ Engl J Med. 2003;348(18):1737-1746.

9. Lexau CA, Lynfield R, Danila R, et al. Changing epidemiology of invasive pneumococcal disease among older adults in the era of pediatric pneumococcal conjugate vaccine. JAMA. 2005;294(16):2043-2051. 
10. Ardanuy C, Tubau F, Pallares R, et al. Epidemiology of invasive pneumococcal disease among adult patients in Barcelona before and after pediatric 7-valent pneumococcal conjugate vaccine introduction, 1997-2007. Clin Infect Dis. 2009;48(1):57-64.

11. Ministerio de Sanidad, Servicios Sociales e Igualdad. 2015. Grupo de trabajo vacunación frente a neumococo en grupos de riesgo 2015 de la Ponencia de Programas y Registro de Vacunaciones. Utilización de la vacuna frente a neumococo en grupos de riesgo. Comisión de Salud Pública del Consejo Interterritorial del Sistema Nacional de Salud. [Working group record of vaccinations and vaccination against Pneumococcus in 2015 for the presentation of program risk groups. Use of the vaccine against Pneumococcus in risk groups. Health committee of the council inter-territorial national health system. Pneumococcal vaccination working group 2015]. Available from: http://www.msssi. gob.es/profesionales/saludPublica/prevPromocion/vacunaciones/docs/ Neumococo_Gruposriesgo.pdf. Accessed October 5, 2017. Spanish

12. Pallares R, Liñares J, Vadillo $M$, et al. Resistance to penicillin and cephalosporin and mortality from severe pneumococcal pneumonia in Barcelona, Spain. N Engl J Med. 1995;333(8):474-480.

13. Vestbo J, Hurd SS, Agustí AG, et al. Global strategy for the diagnosis, management, and prevention of chronic obstructive pulmonary disease GOLD executive summary. Am J Respir Crit Care Med. 2013;187(4):347-365.

14. Domenech A, Ardanuy C, Tercero A, García-Somoza D, Santos S, Liñares J. Dynamics of the pneumococcal population causing acute exacerbations in COPD patients in a Barcelona hospital (2009-12): comparison with 2001-04 and 2005-08 periods. J Antimicrob Chemother. 2014;69(4):932-939.

15. Domenech A, Ardanuy C, Calatayud L, et al. Serotypes and genotypes of Streptococcus pneumoniae causing pneumonia and acute exacerbations in patients with chronic obstructive pulmonary disease. J Antimicrob Chemother. 2011;66(3):487-493.

16. Pauwels RA, Buist AS, Calverley PM, Jenkins CR, Hurd SS; GOLD Scientific Committee. Global strategy for the diagnosis, management, and prevention of chronic obstructive pulmonary disease. NHLBI/ WHO Global Initiative for Chronic Obstructive Lung Disease (GOLD) Workshop summary. Am J Respir Crit Care Med. 2012;163(5): 1256-1276.

17. Clinical and Laboratory Standards Institute. Performance Standards for Antimicrobial Susceptibility Testing; Twenty-Fifth Informational Supplement M100 - S25. Wayne, PA: Clinical and Laboratory Standards Institute; 2017.

18. Clinical and Laboratory Standards Institute. Methods for Dilution Antimicrobial Susceptibility Tests for Bacteria That Grow Aerobically; Approved Standard - Tenth Edition - M07-A10. Wayne, PA: Clinical and Laboratory Standards Institute; 2015.

19. Càmara J, Marimón JM, Cercenado E, et al. Decrease of invasive pneumococcal disease (IPD) in adults after introduction of pneumococcal 13-valent conjugate vaccine in Spain. PLoS One. 2017;12(4):e0175224.
20. Domenech A, Ardanuy C, Pallares R, et al. Some pneumococcal serotypes are more frequently associated with relapses of acute exacerbations in COPD patients. PLoS One. 2013;8(3):e59027.

21. Domenech A, Ardanuy C, Balsalobre L, et al. Pneumococci can persistently colonize adult patients with chronic respiratory disease. $J$ Clin Microbiol. 2012;50(12):4047-4053.

22. McFetridge R, Meulen AS, Folkerth SD, et al. Safety, tolerability, and immunogenicity of 15-valent pneumococcal conjugate vaccine in healthy adults. Vaccine. 2015;33(24):2793-2799.

23. Figueira-Gonçalves JM, Bethencourt-Martín N, Pérez-Méndez LI, et al. Impact of 13-valent pneumococcal conjugate polysaccharide vaccination in exacerbations rate of COPD patients with moderate to severe obstruction. Rev Esp Quimioter. 2017;30(4):269-275.

24. Lindstrand A, Galanis I, Darenberg J, et al. Unaltered pneumococcal carriage prevalence due to expansion of non-vaccine types of low invasive potential 8 years after vaccine introduction in Stockholm, Sweden. Vaccine. 2016;34(38):4565-4571.

25. Hays C, Vermee Q, Agathine A, et al. Demonstration of the herd effect in adults after the implementation of pneumococcal vaccination with PCV13 in children. Eur J Clin Microbiol Infect Dis. 2016;36(5):831-838.

26. Houseman C, Hughes GJ, Chapman KE, Wilson D, Gorton R. Increased invasive pneumococcal disease, North East England, UK. Emerg Infect Dis. 2017;23(1):122-126.

27. Sá-Leao R, Pinto F, Aguiar S, et al. Analysis of invasiveness of pneumococcal serotypes and clones circulating in Portugal before widespread use of conjugate vaccines reveals heterogeneous behavior of clones expressing the same serotype. J Clin Microbiol. 2011;49(4):1369-1375.

28. Aguinagalde L, Corsini B, Domenech A, et al. Emergence of amoxicillin-resistant variants of Spain9V-ST156 pneumococci expressing serotype $11 \mathrm{~A}$ correlates with their ability to evade the host immune response. PLoS One. 2015;10(9):0137565.

29. Rolo D, Fenoll A, Ardanuy C, et al. Trends of invasive serotype 6C pneumococci in Spain: emergence of a new lineage. J Antimicrob Chemother. 2011;66(8):1712-1718.

30. Janoir C, Cohen R, Levy C, et al. Clonal expansion of the macrolide resistant ST386 within pneumococcal serotype 6C in France. PLoS One. 2014;9(3):e90935.

31. Horácio AN, Silva-Costa C, Diamantino-Miranda J, et al. Population structure of Streptococcus pneumoniae causing invasive disease in adults in Portugal before PCV13 availability for adults: 2008-2011. PLoS One. 2016;11(5):e0153602.

32. Segal LN, Clemente JC, Wu BG, et al. Randomised, double-blind, placebocontrolled trial with azithromycin selects for anti-inflammatory microbial metabolites in the emphysematous lung. Thorax. 2017;72(1):13-22.

33. Kapatai G, Sheppard CL, Troxler LJ, et al. Pneumococcal 23B molecular subtype identified using whole genome sequencing. Genome Biol Evol. 2017;9(8):2122-2135.

34. Chewapreecha C, Harris SR, Croucher NJ, et al. Dense genomic sampling identifies highways of pneumococcal recombination. Nat Genet. 2014;46(3):305-309. 


\section{Supplementary materials}

Table SI Serotype distribution among acute exacerbation episodes of COPD patient by period of time

\begin{tabular}{|c|c|c|c|c|c|c|c|c|c|c|}
\hline & \multicolumn{2}{|c|}{ Total } & \multicolumn{2}{|c|}{$2001-2004^{\prime}$} & \multicolumn{2}{|c|}{$2005-2008^{\prime}$} & \multicolumn{2}{|c|}{$2009-2012^{1}$} & \multicolumn{2}{|c|}{$2013-2016$} \\
\hline & $\bar{n}$ & $\%$ & $\bar{n}$ & $\%$ & $\bar{n}$ & $\%$ & $\bar{n}$ & $\%$ & $\bar{n}$ & $\%$ \\
\hline Serotype & 772 & & 136 & & 211 & & 198 & & 210 & \\
\hline PCV7 & 130 & 16.84 & 54 & 39.71 & 37 & I 7.54 & 23 & 11.62 & 16 & $7.62^{\mathrm{a}, \mathrm{b}, \mathrm{d}}$ \\
\hline $19 \mathrm{~F}$ & 45 & 5.83 & 15 & 11.03 & 6 & 2.84 & 13 & 6.57 & II & 5.24 \\
\hline $18 \mathrm{C}$ & 8 & 1.04 & 4 & 2.94 & 2 & 0.95 & 0 & 0.00 & 2 & 0.95 \\
\hline $23 \mathrm{~F}$ & 26 & 3.37 & 9 & 6.62 & 11 & 5.21 & 5 & 2.53 & I & $0.48^{\mathrm{a}, \mathrm{b}, \mathrm{d}}$ \\
\hline $9 \mathrm{~V}$ & 19 & 2.46 & 11 & 8.09 & 5 & 2.37 & 2 & 1.01 & 1 & $0.48^{d}$ \\
\hline $6 \mathrm{~B}$ & 7 & 0.91 & 5 & 3.68 & 1 & 0.47 & 0 & 0.00 & I & $0.48^{\mathrm{a}}$ \\
\hline 14 & 21 & 2.72 & 9 & 6.62 & 10 & 4.74 & 2 & 1.01 & 0 & $0.00^{b, d}$ \\
\hline 4 & 4 & 0.52 & I & 0.74 & 2 & 0.95 & I & 0.51 & 0 & 0.00 \\
\hline PCVI3 & 252 & 32.25 & 75 & 55.15 & 85 & 40.28 & 57 & 27.78 & 35 & $16.19^{c}$ \\
\hline Add PCVI3 & 122 & 14.77 & 21 & 15.44 & 48 & 20.38 & 34 & 16.16 & 19 & 8.57 \\
\hline $19 A$ & 46 & 5.96 & 9 & 6.62 & 14 & 6.64 & 10 & 5.05 & 13 & 6.19 \\
\hline 3 & 51 & 6.61 & 10 & 7.35 & 20 & 9.48 & 16 & 8.08 & 5 & $2.38^{\mathrm{a-d}}$ \\
\hline $7 F$ & 12 & 1.55 & 1 & 0.74 & 7 & 3.32 & 3 & 1.52 & I & $0.48^{b}$ \\
\hline $6 \mathrm{~A}$ & 11 & 1.42 & I & 0.74 & 6 & 2.84 & 4 & 2.02 & 0 & $0.00^{\mathrm{b}-\mathrm{d}}$ \\
\hline 1 & 1 & 0.13 & 0 & 0.00 & 0 & 0.00 & I & 0.51 & 0 & 0.00 \\
\hline 5 & I & 0.13 & 0 & 0.00 & I & 0.47 & 0 & 0.00 & 0 & 0.00 \\
\hline non-PCVI3 & 503 & 67.36 & 61 & 46.32 & 126 & 63.03 & $14 \mid$ & 75.25 & 175 & $83.33^{b}$ \\
\hline IIA & 57 & 7.38 & 10 & 7.35 & 12 & 5.69 & 12 & 6.06 & 23 & $10.95^{b, d}$ \\
\hline $6 C$ & 41 & 5.31 & 0 & 0.00 & 9 & 4.27 & 11 & 5.56 & 21 & $10.00^{b}$ \\
\hline 31 & 31 & 4.02 & 4 & 2.94 & 9 & 4.27 & 5 & 2.53 & 13 & 6.19 \\
\hline $23 \mathrm{~A}$ & 32 & 4.15 & 4 & 2.94 & 9 & 4.27 & 9 & 4.55 & 10 & 4.76 \\
\hline $15 B / C$ & 18 & 2.33 & 1 & 0.74 & 2 & 0.95 & 6 & 3.03 & 9 & $4.29^{\mathrm{b}, \mathrm{d}}$ \\
\hline $23 B$ & 27 & 3.50 & 5 & 3.68 & 5 & 2.37 & 9 & 4.55 & 8 & 3.81 \\
\hline $35 B$ & 26 & 3.37 & 3 & 2.21 & 8 & 3.79 & 7 & 3.54 & 8 & 3.81 \\
\hline $10 \mathrm{~A}$ & 25 & 3.24 & 2 & 1.47 & 7 & 3.32 & 8 & 4.04 & 8 & 3.81 \\
\hline $24 \mathrm{~F}$ & 17 & 2.20 & I & 0.74 & 3 & 1.42 & 5 & 2.53 & 8 & 3.81 \\
\hline $16 \mathrm{~F}$ & 29 & 3.76 & 7 & 5.15 & 8 & 3.79 & 7 & 3.54 & 7 & 3.33 \\
\hline $15 \mathrm{~A}$ & 34 & 4.40 & 3 & 2.21 & 6 & 2.84 & 19 & 9.60 & 6 & $2.86^{c}$ \\
\hline $22 \mathrm{~F}$ & 24 & 3.11 & 3 & 2.21 & 9 & 4.27 & 6 & 3.03 & 6 & 2.86 \\
\hline 9L/N & 12 & 1.55 & 1 & 0.74 & 3 & 1.42 & 3 & 1.52 & 5 & 2.38 \\
\hline $35 \mathrm{~F}$ & 16 & 2.07 & 2 & 1.47 & 7 & 3.32 & 3 & 1.52 & 4 & 1.90 \\
\hline $33 \mathrm{~F}$ & 18 & 2.33 & 6 & 4.41 & 5 & 2.37 & 6 & 3.03 & I & $0.48^{\mathrm{a}, \mathrm{d}}$ \\
\hline $17 F$ & 11 & 1.42 & 0 & 0.00 & 3 & 1.42 & 6 & 3.03 & 2 & 0.95 \\
\hline 34 & 8 & 1.04 & 0 & 0.00 & 4 & 1.90 & 2 & 1.01 & 2 & 0.95 \\
\hline 8 & 3 & 0.39 & 0 & 0.00 & 1 & 0.47 & 0 & 0.00 & 2 & 0.95 \\
\hline 21 & 10 & 1.30 & 2 & 1.47 & 4 & 1.90 & 4 & 2.02 & 0 & $0.00^{c}$ \\
\hline $12 \mathrm{~F}$ & 8 & 1.04 & I & 0.74 & 4 & 1.90 & 3 & 1.52 & 0 & 0.00 \\
\hline 38 & 5 & 0.65 & 0 & 0.00 & 5 & 2.37 & 0 & 0.00 & 0 & $0.00^{b}$ \\
\hline 20 & 5 & 0.65 & I & 0.74 & 2 & 0.95 & 2 & 1.01 & 0 & 0.00 \\
\hline NT & 27 & 3.50 & 0 & 0.00 & 0 & 0.00 & 4 & 2.02 & 23 & 10.95 \\
\hline Others & 19 & 2.46 & 5 & 3.68 & 1 & 0.47 & 4 & 2.02 & 9 & 4.29 \\
\hline
\end{tabular}

Notes: Significant changes comparing current (2013-2016) period with previous periods: a2001-2004; '2005-2008; c2009-2012; '200I-2012. Data of the historical period were previously published in Domenech et al.' Values shown in bold indicate the significant data.

Abbreviations: COPD, chronic obstructive pulmonary disease; NT, non-typeable; PCV7, 7-valent pneumococcal conjugate vaccine; PCVI3, I3-valent pneumococcal conjugate vaccine. 
Table S2 Clonal composition of major serotypes causing invasive and noninvasive diseases in COPD patients (20I3-20I6)

\begin{tabular}{|c|c|c|c|c|c|}
\hline \multirow[t]{2}{*}{ Serotype } & \multirow[t]{2}{*}{ Clonal complex } & \multirow{2}{*}{$\frac{\text { IPD }}{n}$} & \multirow{2}{*}{$\begin{array}{l}\text { Non-BPP } \\
\mathrm{n}\end{array}$} & \multirow{2}{*}{$\begin{array}{l}\text { AE-COPD } \\
n\end{array}$} & \multirow{2}{*}{$\begin{array}{l}\text { Total } \\
n\end{array}$} \\
\hline & & & & & \\
\hline \multirow[t]{4}{*}{ IIA } & Total & 3 & 7 & 23 & 33 \\
\hline & $\mathrm{CCl} 56$ & 2 & 5 & 19 & 26 \\
\hline & $\mathrm{CC} 62$ & $\mathrm{I}$ & 1 & 4 & 6 \\
\hline & Others & 0 & 1 & 0 & I \\
\hline \multirow[t]{4}{*}{3} & Total & 8 & 13 & 5 & 26 \\
\hline & $\mathrm{CCl} 80$ & 5 & 9 & 3 & 17 \\
\hline & $\mathrm{CC} 260$ & 2 & 4 & 2 & 8 \\
\hline & Others & I & 0 & 0 & 1 \\
\hline \multirow[t]{6}{*}{$6 \mathrm{C}$} & Total & 0 & 4 & 21 & 25 \\
\hline & CC386 & 0 & 3 & 18 & 21 \\
\hline & CC224 & 0 & 0 & 1 & 1 \\
\hline & $\mathrm{CCl} 692$ & 0 & 0 & 1 & 1 \\
\hline & CC2690 & 0 & 1 & 0 & 1 \\
\hline & Others & 0 & 0 & 1 & 1 \\
\hline \multirow[t]{7}{*}{$19 A$} & Total & 3 & 5 & 13 & 21 \\
\hline & $\mathrm{CC} 320$ & 0 & 3 & 7 & 10 \\
\hline & $\mathrm{CC} 230$ & 0 & 0 & 2 & 2 \\
\hline & $\mathrm{CCl} 99$ & 1 & 1 & 0 & 2 \\
\hline & $\mathrm{CCl} 93$ & 0 & 1 & I & 2 \\
\hline & $\mathrm{CC} 8 \mathrm{I}$ & 1 & 0 & 1 & 2 \\
\hline & Others & 1 & 0 & 2 & 3 \\
\hline \multirow[t]{2}{*}{31} & Total & 3 & 4 & 13 & 20 \\
\hline & $\mathrm{CCI} 684$ & 3 & 4 & 13 & 20 \\
\hline \multirow[t]{4}{*}{$23 \mathrm{~A}$} & Total & 3 & 6 & 10 & 19 \\
\hline & CC42 & 0 & 4 & 7 & 11 \\
\hline & CC2670 & 2 & 2 & 2 & 6 \\
\hline & Others & I & 0 & 1 & 2 \\
\hline \multirow[t]{4}{*}{$35 B$} & Total & 2 & 5 & 8 & 15 \\
\hline & CC2690 & 1 & 0 & 2 & 3 \\
\hline & CC558 & 1 & 0 & 1 & 2 \\
\hline & Others & 0 & 5 & 5 & 10 \\
\hline \multirow[t]{4}{*}{8} & Total & 8 & 4 & 2 & 14 \\
\hline & $\mathrm{CC} 53$ & 4 & 3 & 1 & 8 \\
\hline & CC404 & 3 & I & 1 & 5 \\
\hline & СС3500 & 1 & 0 & 0 & 1 \\
\hline \multirow[t]{2}{*}{$9 \mathrm{~L} / \mathrm{N}$} & Total & 3 & 6 & 5 & 14 \\
\hline & CC67 & 3 & 6 & 5 & 14 \\
\hline \multirow[t]{3}{*}{$23 B$} & Total & 3 & 2 & 8 & 13 \\
\hline & CC338 & 3 & 0 & 0 & 3 \\
\hline & CC2372 & 0 & 2 & 8 & 10 \\
\hline \multirow[t]{3}{*}{ IOA } & Total & 2 & 2 & 8 & 12 \\
\hline & CC97 & 1 & 2 & 7 & 10 \\
\hline & Others & 1 & 0 & 1 & 2 \\
\hline \multirow[t]{4}{*}{ I5BC } & Total & 0 & 3 & 9 & 12 \\
\hline & $\mathrm{CCl} 262$ & 0 & 2 & 6 & 8 \\
\hline & $\mathrm{CCl} 99$ & 0 & 1 & I & 2 \\
\hline & Others & 0 & 0 & 2 & 2 \\
\hline $19 \mathrm{~F}$ & Total & 1 & 0 & 11 & 12 \\
\hline & CC202 & 0 & 0 & 2 & 2 \\
\hline & $\mathrm{CCl} 79$ & 0 & 0 & 1 & 1 \\
\hline & CC87 & 0 & 0 & 1 & 1 \\
\hline & CC90 & 0 & 0 & I & 1 \\
\hline & CC8359 & 0 & 0 & 3 & 3 \\
\hline & Others & 1 & 0 & 3 & 4 \\
\hline
\end{tabular}


Table S2 (Continued)

\begin{tabular}{|c|c|c|c|c|c|}
\hline \multirow[t]{2}{*}{ Serotype } & \multirow[t]{2}{*}{ Clonal complex } & \multirow{2}{*}{$\frac{\text { IPD }}{n}$} & \multirow{2}{*}{$\begin{array}{l}\text { Non-BPP } \\
\mathrm{n}\end{array}$} & \multirow{2}{*}{$\begin{array}{l}\text { AE-COPD } \\
n\end{array}$} & \multirow{2}{*}{$\begin{array}{l}\text { Total } \\
\mathrm{n} \\
\end{array}$} \\
\hline & & & & & \\
\hline \multirow[t]{3}{*}{$16 \mathrm{~F}$} & Total & 0 & 3 & 7 & 10 \\
\hline & СС30 & 0 & 2 & 6 & 8 \\
\hline & Others & 0 & 1 & 1 & 2 \\
\hline \multirow[t]{3}{*}{$22 \mathrm{~F}$} & Total & 2 & 2 & 6 & 10 \\
\hline & CC433 & I & 2 & 5 & 8 \\
\hline & Others & I & 0 & I & 2 \\
\hline \multirow[t]{2}{*}{$24 \mathrm{~F}$} & Total & 0 & 0 & 8 & 8 \\
\hline & CC230 & 0 & 0 & 8 & 8 \\
\hline \multirow[t]{3}{*}{$12 \mathrm{~F}$} & Total & 5 & 1 & 0 & 6 \\
\hline & CС989 & 4 & I & 0 & 5 \\
\hline & $\mathrm{CCI} 766$ & 1 & 0 & 0 & 1 \\
\hline \multirow[t]{3}{*}{$15 \mathrm{~A}$} & Total & 0 & 0 & 6 & 6 \\
\hline & $\mathrm{CC} 63$ & 0 & 0 & 4 & 4 \\
\hline & Others & 0 & 0 & 2 & 2 \\
\hline \multirow[t]{3}{*}{$17 F$} & Total & 2 & 2 & 2 & 6 \\
\hline & CC392 & 2 & 1 & I & 4 \\
\hline & Others & 0 & 1 & 1 & 2 \\
\hline \multirow[t]{4}{*}{$35 \mathrm{~F}$} & Total & 0 & 1 & 4 & 5 \\
\hline & $\mathrm{CC} 2615$ & 0 & 0 & 3 & 3 \\
\hline & $\mathrm{CCl} 635$ & 0 & 0 & I & 1 \\
\hline & Others & 0 & 1 & 0 & I \\
\hline
\end{tabular}

Abbreviations: AE-COPD, acute exacerbation of COPD; COPD, chronic obstructive pulmonary disease; IPD, invasive pneumococcal disease; non-BPP, non-bacteremic pneumococcal pneumonia. 
Table S3 Changes in the clonal composition of pneumococci causing AE-COPD

\begin{tabular}{|c|c|c|c|c|c|c|c|c|c|c|}
\hline \multirow{2}{*}{$\begin{array}{l}\text { Clonal } \\
\text { complex }\end{array}$} & \multirow{2}{*}{$\begin{array}{l}\text { Number } \\
\text { of isolates }\end{array}$} & \multirow{2}{*}{$\begin{array}{l}\text { Serotype related } \\
\text { (number of isolates) }\end{array}$} & \multicolumn{2}{|c|}{$2001-2004^{\prime}$} & \multicolumn{2}{|c|}{ 2005-2008' } & \multicolumn{2}{|c|}{$2009-2012^{\prime}$} & \multicolumn{2}{|c|}{$2013-2016$} \\
\hline & & & 136 & $(\%)$ & 211 & $(\%)$ & 198 & $(\%)$ & 210 & (\%) \\
\hline \multirow[t]{3}{*}{156} & 54 & $9 V(16)$ & 10 & 7.4 & 4 & 1.9 & I & 0.5 & 0 & 0.0 \\
\hline & & $14(16)$ & 7 & 5.1 & 7 & 3.3 & 2 & 1.0 & I & 0.5 \\
\hline & & IIA (22) & 0 & 0.0 & 0 & 0.0 & 3 & 1.5 & 19 & 9.0 \\
\hline \multirow[t]{3}{*}{63} & 35 & I5A (30) & 3 & 2.2 & 6 & 2.8 & 17 & 8.6 & 4 & 1.9 \\
\hline & & I9F (4) & 2 & 1.5 & 1 & 0.5 & 1 & 0.5 & 0 & 0.0 \\
\hline & & $15 F(I)$ & I & 0.7 & 0 & 0.0 & 0 & 0.0 & 0 & 0.0 \\
\hline 62 & 31 & IIA (3I) & 9 & 6.6 & 10 & 4.7 & 8 & 4.0 & 4 & 1.9 \\
\hline 180 & 28 & $3(28)$ & 7 & 5.1 & 9 & 4.3 & 9 & 4.5 & 3 & 1.4 \\
\hline 30 & 27 & I6F (27) & 6 & 4.4 & 8 & 3.8 & 7 & 3.5 & 6 & 2.9 \\
\hline \multirow[t]{3}{*}{42} & 27 & $23 \mathrm{~A}(25)$ & 4 & 2.9 & 10 & 4.7 & 5 & 2.5 & 7 & 3.3 \\
\hline & & $19 A(I)$ & 0 & 0.0 & 1 & 0.5 & 0 & 0.0 & 0 & 0.0 \\
\hline & & $23 \mathrm{~F}(\mathrm{I})$ & 0 & 0.0 & I & 0.5 & 0 & 0.0 & 0 & 0.0 \\
\hline 386 & 25 & $6 \mathrm{C}(24), 6 \mathrm{~A}(\mathrm{I})$ & 0 & 0.0 & 0 & 0.0 & 7 & 3.5 & 18 & 8.6 \\
\hline \multirow[t]{3}{*}{81} & 22 & $23 F(I 2)$ & 7 & 5.1 & 5 & 2.3 & 0 & 0.0 & 0 & 0.0 \\
\hline & & $19 A(6)$ & 3 & 2.2 & I & 0.5 & I & 0.5 & I & 0.5 \\
\hline & & I9F (4) & 2 & 1.4 & 2 & 0.9 & 0 & 0.0 & 0 & 0.0 \\
\hline 97 & 22 & $10 A(22)$ & 2 & 1.5 & 5 & 2.4 & 8 & 4.0 & 7 & 3.3 \\
\hline 260 & 18 & $3(18)$ & 2 & 1.5 & 7 & 3.3 & 7 & 3.5 & 2 & 1.0 \\
\hline \multirow[t]{2}{*}{230} & 17 & $24 \mathrm{~F}(\mathrm{I})$ & 0 & 0.0 & 3 & 1.4 & 3 & 1.5 & 8 & 3.8 \\
\hline & & 19A (3) & 0 & 0.0 & I & 0.5 & 0 & 0.0 & 2 & 1.0 \\
\hline 433 & 15 & $22 \mathrm{~F}(\mathrm{I} 5)$ & 1 & 0.7 & 7 & 3.2 & 2 & 1.0 & 5 & 2.4 \\
\hline 320 & 14 & I9A (I4) & 0 & 0.0 & 1 & 0.5 & 6 & 3.0 & 7 & 3.3 \\
\hline 1684 & 23 & $31(23)$ & $\mathrm{I}$ & 0.7 & 5 & 2.4 & 4 & 2.0 & 13 & 6.2 \\
\hline 88 & 11 & I9F (II) & 5 & 3.7 & 3 & 1.4 & 3 & 1.5 & 0 & 0.0 \\
\hline \multirow[t]{2}{*}{558} & 11 & $35 B(8)$ & I & 0.7 & 2 & 0.9 & 4 & 2.0 & I & 0.5 \\
\hline & & $35 F(3)$ & 1 & 0.7 & 2 & 0.9 & 0 & 0.0 & 0 & 0.0 \\
\hline 3548 & 10 & $31(10)$ & I & 0.7 & 5 & 2.4 & 4 & 2.0 & 0 & 0.0 \\
\hline 717 & 11 & $33 F(10)$ & 3 & 2.2 & 2 & 0.9 & 5 & 2.5 & 1 & 0.5 \\
\hline 191 & 10 & $7(10)$ & 1 & 0.7 & 5 & 2.4 & 3 & 1.5 & 1 & 0.5 \\
\hline 67 & 10 & 9L/N (9), I4 (I) & 2 & 1.5 & I & 0.5 & 2 & 1.0 & 5 & 2.4 \\
\hline 432 & 8 & $21(8)$ & 2 & 1.5 & 4 & 1.9 & 2 & 1.0 & 0 & 0.0 \\
\hline 338 & 18 & $23 \mathrm{~B}(8)$ & 2 & 1.5 & 2 & 0.9 & 6 & 3.0 & 8 & 3.8 \\
\hline 989 & 7 & $12 F(7)$ & 1 & 0.7 & 4 & 1.9 & 2 & 1.0 & 0 & 0.0 \\
\hline 110 & 7 & $18 C(7)$ & 4 & 2.9 & 2 & 0.9 & 0 & 0.0 & 1 & 0.5 \\
\hline $120 \mid$ & 6 & I9A (6) & 1 & 0.7 & 3 & 1.4 & 2 & 1.0 & 0 & 0.0 \\
\hline 392 & 6 & I7F (6) & 0 & 0.0 & I & 0.5 & 4 & 2.0 & I & 0.5 \\
\hline 1262 & 6 & $15 B C(6)$ & 0 & 0.0 & 0 & 0.0 & 0 & 0.0 & 6 & 2.9 \\
\hline 177 & 5 & $19 F(5)$ & 1 & 0.7 & 0 & 0.0 & 4 & 2.0 & 0 & 0.0 \\
\hline \multirow[t]{2}{*}{90} & 5 & 6B (4) & 3 & 2.2 & I & 0.5 & 0 & 0.0 & 0 & 0.0 \\
\hline & & $19 F(I)$ & 0 & 0.0 & 0 & 0.0 & 0 & 0.0 & I & 0.5 \\
\hline
\end{tabular}

Note: Data of the historical period were previously published in part in Domenech et al.'

Abbreviation: AE-COPD, acute exacerbation of chronic obstructive pulmonary disease.

\section{Reference}

1. Domenech A, Ardanuy C, Tercero A, García-Somoza D, Santos S, Liñares J. Dynamics of the pneumococcal population causing acute exacerbations in COPD patients in a Barcelona hospital (2009-12): comparison with 2001-04 and 2005-08 periods. JAntimicrob Chemother. 2014;69(4):932-939.

Infection and Drug Resistance

\section{Publish your work in this journal}

Infection and Drug Resistance is an international, peer-reviewed openaccess journal that focuses on the optimal treatment of infection (bacterial, fungal and viral) and the development and institution of preventive strategies to minimize the development and spread of resistance. The journal is specifically concerned with the epidemiology of antibiotic

resistance and the mechanisms of resistance development and diffusion in both hospitals and the community. The manuscript management system is completely online and includes a very quick and fair peerreview system, which is all easy to use. Visit http://www.dovepress.com/ testimonials.php to read real quotes from published authors. 